\title{
Farklı Ses Dosyası Formatlarının İşitsel Algısı
}

Feridun Öziş*

Özet

Günümüzde kaydedilmiş müziğin dinlenmesinde birçok farklı parametreler söz konusudur. Genel olarak iki temel tablo karşımıza çıkar. Bunlardan ilki ev, bar, club gibi kapalı mekanlar ve açık konser alanlarında ses sistemlerinden müzik dinlenmesidir. Ikinci bölümde ise kulaklıklarla müzik dinleme pratiği yer alır. Her iki durum için de geçerli olan temel kriter, elbette müzik dinlenilen ses sisteminin ya da kulaklığın kalitesidir. Günümüzde çok farklı kaliteye sahip ses sistemleri ve kulaklıklar tüketiciye sunulmuştur. Bu pratikler içerisinde temel bir diğer belirleyici ise, ses sistemi ya da kulaklıktan bağımsız olarak playback ekipmanda bulunan audio örneğinin kalitesidir. İnternet ortamında birçok farklı kalitede örnek bulmak mümkündür. Bu noktadan hareketle, farklı audio örneklerinin dinleyici tarafından nasıl algılandığı, daha açık bir ifadeyle, değişik formatlarda kaydedilmiş sinyaller arasındaki farkın dinleyici tarafından algılanıp algılanmadığı önemli bir araştırma konusudur. Bu metin, farklı audio örnekleriyle ilişkili öznel testler yaparak, bu formatların dinleyici grupları tarafından ayırdedilip edilmediğini araştırmayı amaçlamaktadır. Deney kapsamında altı farklı uluslararası sanat müziği enstrumanı ve eseri için beş faklı audio formatı belirlenmiş, bunlardan üretilen yedi adet karşılaştırma çifti katılımcılara dinletilmiştir. Bu çerçevede kulak eğitimli katılımcıların audio kodek farklılıklarını hangi seviyede algıladıkları araştırılmıştır.

Anahtar Sözcükler: Audio Formatları, Ses Kalitesi, Müzik Algısı.

\section{Audio Perception of Different File Formats}

Abstract

Nowadays, there are different parameters in listening recorded music. Generally, there are two basic scenarios. The first scenario is listening to music through some kind of sound system in closed spaces like homes, bars, clubs etc. and listening to concerts in open areas. The second scenario is listening to music through headphones. The basic criteria affecting both of these scenarios is the quality of the audio reproduction system or the headphone and there are lots of different systems with different qualities. There is one more parameter regardless of the quality of the audio system or the headphone, being the quality of the audio sample itself. There are various audio samples with different qualities in the internet. Taking this into perspective, the perception of different audio encoding formats and whether or not the differences between the formats are being perceived is an important research subject. This paper aims to find out if these differences are being perceived by listener groups, with subjective tests using various audio samples. For the comparison tests, seven pairs of audio samples have been prepared in five encoding formats, for six different classical music instruments. With these comparison tests, this study investigates in which level participants with ear training education can identify the differences between audio codec formats.

Keywords: Audio Formats, Sound Quality, Music Perception. 


\section{Giriş}

Ses kalitesi kavramı karmaşık ve çok katmanlı bir kavramdır. Duyduğumuz sesin kalitesinde, playback ekipmanlarından dinleme yapılan odanın akustik karakterine kadar birçok parametre etkendir. Toplamda duyduğumuz ses, her bir ekipmanın ve odanın frekans karakteristiklerinin toplamı olarak değerlendirilebilir.

1991'de Motion Picture Expert Group tarafindan 'kayıplı ses standartı’ olarak piyasaya sürülen Mp3 formatı, dijital müzik verilerinin kapladığı alanın azaltılması amacıyla ortaya çıkmıştır.(Blauert ve Ute, 2012: 4) Günümüzde farklı teknikler kullanan sıkıştırma formatları aktif olarak kullanılmaktadır. Bunun temel sebebi, Mp3 formatının veri büyüklüğünün orijinal Wav formatından çok daha küçük olması ve bu sayede depolama birimlerinde çok daha az yer tutmasıdır. Veri alanının küçük olması internet üzerinden indirilmesini de kolaylaştırmaktadır. Bu kolaylık, çoğu dinleyicinin bu formatta müzik dinlemesini de beraberinde getirmiştir. Ancak, aylarla ifade edilen sürelerde kayıt edilen, bu süreçte birçok farklı kayıt tekniğinin kullanıldığı ve ses mühendislerinin toplam sound'un doğru duyulabilmesi için gerçekleştirdiği birçok işlem Mp3 formatında duyulamamaktadır. Sonuçta dinlenilen müzik ile kaydedilen arasında ciddi farklar oluşmakta ve bu, dinlenilen unsurun gerçekte olduğundan farkı ı duyulmasına yol açmaktadır.

Günümüzde ses kalitesi üzerine farklı alanlarda birçok çalışma gerçekleştirilmiştir. Yapılan ilk çalışma R. E. Kirk tarafından 1956'da gerçekleştirilmiştir. Kirk'ün çalışmasında öğrencilerin günlük hayatlarında "dar" frekans cevabına sahip hoparlörleri tercih ettikleri ortaya çıkmış, ancak daha geniş bantlı hoparlörlerle belirli bir süre dinleme yaptıktan sonra tercihlerini bu yöne kaydırdıkları gözlemlenmiştir (Kirk, 1956: 1116). Yapılan diğer bir çalışma, eğitimli dinleyicilerin audio formatlarındaki bozulmayı değerlendirdikleri çalışmadı (Soulodre, Grusec, Lavoie, Thibault, 1998:177). Bu çalışmada, MPEG ve Dolby gibi farklı ses formatları karşılaştırılmıştır. Yakın tarihli bir diğer incelemeyse, kolej öğrencilerinin CD-Mp3 (düşük kaliteli) tercihleri üzerine gerçekleştirilmiştir (Oli- ve, 2012: 6). Bu çalışmada öğrencilerin yüksek miktarda CD kalitesini tercih ettikleri ortaya konmuştur. Hamburg Üniversitesi'nde yapılan bir diğer çalışmada ise, farklı Mp3 formatlarıyla CD kalitesi karşılaştırıımıştır (Böhne vd, 2011: 6). Bu çalışmada da, deneklerin wav formatını, sıkıştırılmış Mp3 formatına tercih ettikleri ortaya çıkmıştır.

Bu çalışma, uluslararası sanat müziği enstruman ve eserleri çerçevesinde, solo enstrumanların ve çok sesli müzik örneklerinin farklı audio formatlarında, konservatuvar lisans seviyesindeki öğrenciler tarafından nasıl algılandığını ortaya koymayı amaçlamaktadır.

\section{Yöntem}

Yapılacak çalışmada oda karakteristiği ve buna bağlı akustik parametrelerin değerlendirme dışı bırakılabilmesi için dinleme testleri kulaklıkla gerçekleştirildi. Dinleme sinyal yolu Adobe Audition CS6, Focusrite Pro 40 ses kartı, Stax SRM-212 pre-amplifikatör ve Stax SR 202 kulaklık ile oluşturuldu. Bu noktada seçilen ekipmanları frekans karakteristiklerinin mümkün olduğunca düz olması dikkate alındı (Şekil 1).

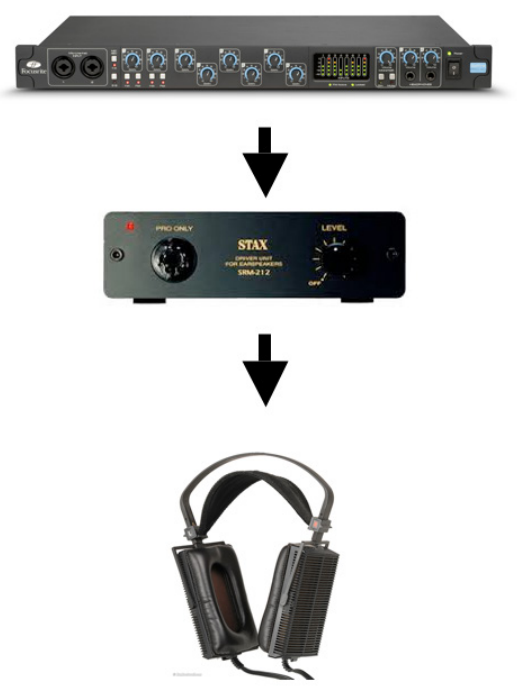

Şekil 1 Dinleme Sinyal Yolu

\section{Test Süreci}

Katılımcılar 18-25 yaş aralığında konservatuvar lisans öğrencilerinden seçildi. Konservatuvar eğitiminin ilko- 
kuldan sonra başladığı düşünüldüğünde, deneklerin tümünün minimum yedi yıl enstruman eğitimi aldığı söylenebilir. Bu noktada katılımcı çeşitliliğinin sağlanabilmesi amacıyla katılımcıların farklı dallarda eğitim almış olmasına dikkat edildi. Toplamda 20 katılımcı üzerinde testler gerçekleştirildi.

Deneyde kullanılan audio örnekleri Wav olarak elde edildikten sonra 96 KHz, 192 KHz, 320 KHz Mp3 ve Flac formatlarına dönüştürüldü. Audio örnekleri 4 solo enstruman (Çello, viyola, keman ve kontrabas), bir yaylı dördül (quarted) ve bir sinfoni olarak belirlendi. Bu sayede farklı formattaki auido örneklerinin solo ve çok sesli eserlerde nasıl algılanacağı değerlendirildi. Tüm eserlerden 30 sn'lik örnekler alındı ve katılımcılar değerlendirmelerini bu örnekler üzerinde gerçekleştirdi. Bu beş farklı formattan 7 farklı çift üretilerek katıımcıların her bir çiftte değerlendirme yapmaları istendi. Ortalama test süresi 30 -45 dakika aralığında gerçekleşti.

\section{Verilerin Analizi}

Değerlendirilen bu çiftte iki düşük kalite Mp3 formatı karşılaştırılmıştır (Şekil 2). Bu noktada her iki formatta da yüksek oranda kayıp olduğu söylenebilir. 96Mp3-192Mp3 karşılaştırmasında en yüksek doğruluk oranının 14 doğru ile kontrabas enstrümanında olduğu görülmektedir Daha sonra, en yüksek yüzdenin yaylı dördülde elde edildiği görülmüştür. Kontrabas ve yaylı dördül dışında kalan ciftlerde yaklaşık \%47 seviyesinde bir başarı vardır.

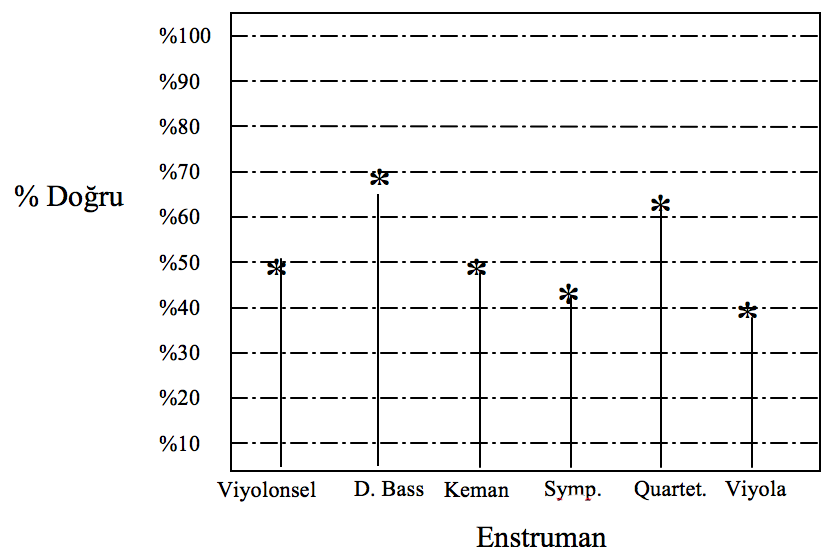

Şekil 2 96Mp3-192 Mp3 Karşılaştırması
Wav -96Mp3 karşılaştırması duyulabilir kodek farkıılığının en yüksek seviyede olduğu karşılaştırmadır (Şekil 3). Bu noktada frekans aralığı en yüksek olan sinfoni eseri \%68 doğruluk oranına sahiptir. Daha sonra gelen yaylı dördül ve kontrabas da bu değer \% 65 seviyesindedir.

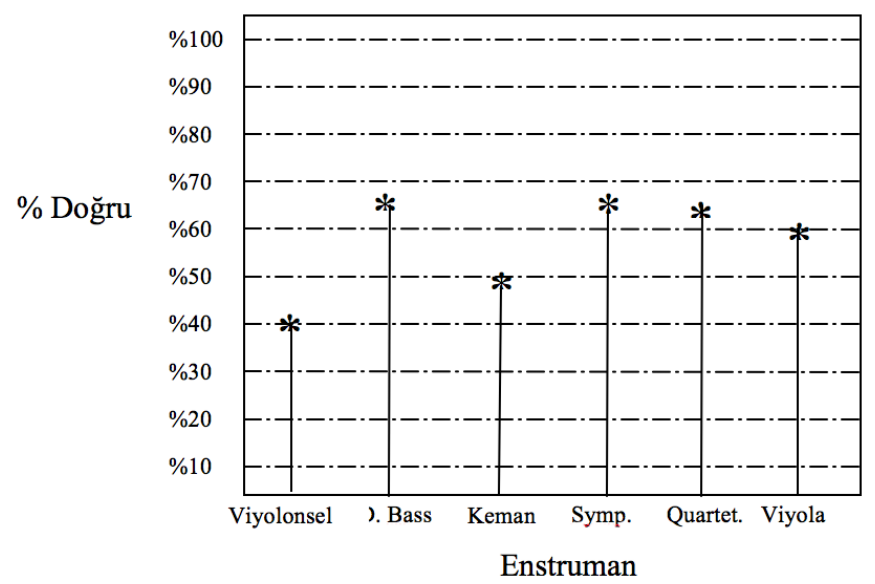

Şekil 396 Mp3-Wav Karşılaştırması

Bu karşılaştırma düşük ve yüksek kalite Mp3 değerlendirmesidir (Şekil 5). 96 Mp3-320 Mp3 karşılaştırmasında yine en yüksek değerin yaylı dördül ve sinfoni de elde edildiği gözlemlenmiştir. Bu noktada deneklerin yüksek kalite Mp3 tercihlerinin \% 59 oranında olduğu görülmüştür.

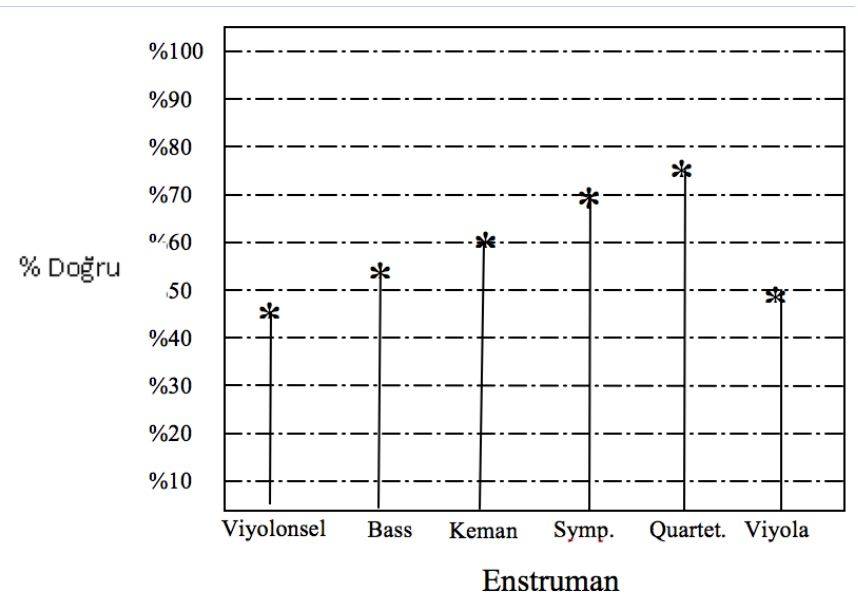

Şekil 4 96Mp3-320Mp3 Karşılaştırması 
192Mp3-320Mp3 ve 192-Wav karşılaştırmaları genel ortalamalar olarak birbirlerine yakın miktarlarda doğruluk oranına sahiptir. Bu 320Mp3 ve Wav sinyallerinin birbirlerine çok yakın olmasından kaynaklanmaktadır. 192Mp3320Mp3 karşılaştırmasında viyolonsel, 192-Wav karşılaştırmasında ise kontrabas en yüksek doğruluk oranına sahiptir (Şekil 6-7).

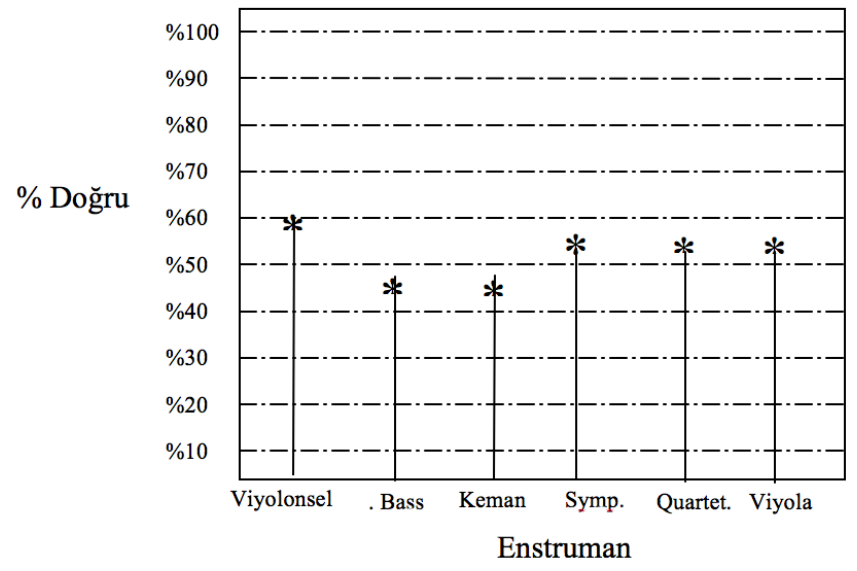

Şekil 5 192Mp3-320Mp3 Karşılaştırması

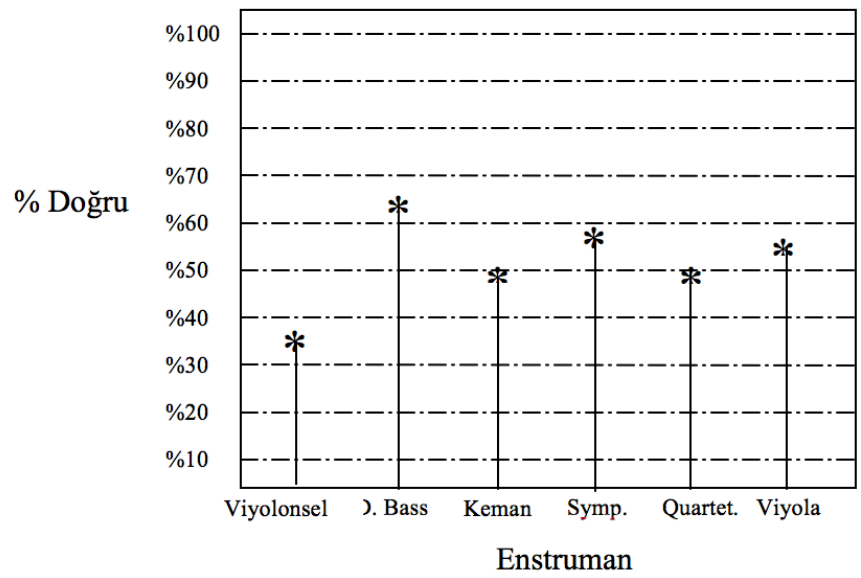

Şekil 6192 Mp3-Wav Karşılaştırması

Wav-320 ve Flac-Wav karşılaştırmaları bir arada değerlendirilebilir niteliktedir (Şekil 8-9). Her iki karşılaştırmada da viyolonsel en iyi doğruluk oranına sahiptir. Flac-Wav karşılaştırmasında viyolonsel, kontrabas yaylı dördül ve sinfoni sıralaması kodek farklılıklarında bas enerjisinin kaybolması sorununa işaret etmesi açısından önemlidir.

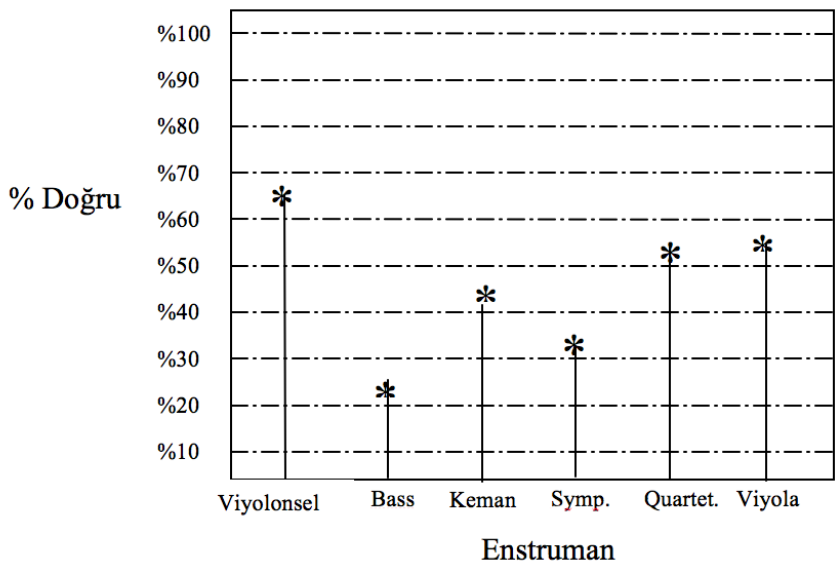

Şekil 7 Wav-320 Mp3 Karşılaştırması

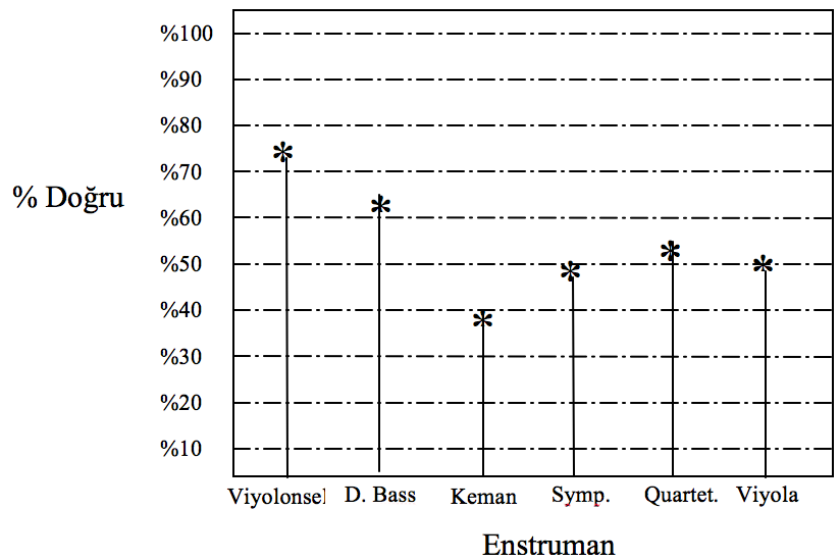

Şekil 8 Flac-Wav karşılaştırması

\section{Sonuç}

Enstrumanların genel doğruluk oranları değerlendirildiğinde \%56 doğruluk oranıyla yaylı dördül ilk sırada yer almaktadır (Tablo 1). Solo enstrumanlarda genel doğruluk miktarı \%50 iken bu değer çok sesli eserlerde \%55 olarak karşımıza çıkar. Bu noktada azda olsa değerlendirilen toplam frekans alanı artışının audio kodek farklarını daha çok ortaya çıkardığı söylenebilir.

Kodek farklılıklarının en yüksek olduğu 96Mp3-Wav ve $96 \mathrm{Mp3}-320 \mathrm{Mp} 3$ değerlerinde en yüksek doğruluk oranı yaylı dördül ve sinfonide elde edilmiştir. Bu çok sesli 


\begin{tabular}{ccccccc} 
Enstruman & Viyolonsel & Keman & Kontrabas & Viyola & Sinfoni & Y. Dördül \\
\hline \% Doğruluk & $\% 53$ & $\% 48$ & $\% 55$ & $\% 51$ & $\% 54$ & $\% 56$ \\
& & & & & \\
& & Tablo 1 Enstrumanların Genel Doğruluk Oranları & &
\end{tabular}

eserlerin solo enstrumanlara göre kodek farklarını daha çok ortaya çıkardığının bir göstergesidir.

Test sürecinde elde edilen önemli verilerden biri kontrabas viyolonsel gibi bas enerjisi yüksek solo ensteumanlarda kodek farklılıklarının daha iyi algılandı̆̆ıdır. Kontrabas ve viyolonsel doğruluk oranı \%54 seviyesindedir.

Deneylerdeki genel başarı oranı değerlendirildiğinde minimum 7 yıl enstruman eğitimi alan öğrencilerin \%56 seviyesinde bir başarı oranı elde etmesi iyi bir sonuç olarak değerlendirilemez. Bu, konservatuvar öğrencilerinin uluslararası sanat müziği eserleri ve çalgılarıyla ilişkili kritik dinleme pratiklerinin zayıf olduğunun bir göstergesi olarak değerlendirilebilir.

\section{Kaynakça}

Blauert, Jens ve Jecosch, Ute (2012). "A Layer Model of Sound Quality", Journal of Audio Engineering Society (60-1/2): 4-12.

Kirk, R. E. (1956). “Learning, A Major Factor Influencing Preferences for High- Fidelity ReproducingSystems”, Journal of Acoustic Society of America (28-6): 1113-1116.

Soulodre, G. A.; Grusec, T.; Lavoie, M.;, Thibault, L. (1998). "Subjective Evaluation of

State-of-the-Art, 2-Channel Audio Kodeks," Journal of Audio Engineering Society (46-3): 164-177.

Olive, Sean (2012). "Some New Evidence that Teenagers and College Students May

Prefer Accurate Sound Reproduction" 132. AES Convention, Budapest, s: 1-15.

\section{Internet Kaynakları}

Böhne, Hendrik; Gröger, René; Hammerschmidt, David; Helm, Robin; Hoga, David;

Kraus, Julian; Rösch, Jakob; Sussek, Christian (2011). “Subjective Audibility of MP3-Compression Artefacts in Practical Application“, Results of Praktikum Musikpsychologie, Proje Başkanı: Prof. Rolf Bader, Institute of Musichology, Hamburg University. http://saungauk.systmuwi.de/wp-content/uploads/2011/11/ TechnicalReport_MP3.pdf (07.10.2014) 